\title{
TOWARDS A SINGLE DEGREE OF FREEDOM (SDOF) MODEL FOR PREDICTING BLAST PERFORMANCE OF CROSS-LAMINATED TIMBER
}

\author{
KATHRYN SANBORN, NOEL FLORES, RUSSELL GENTRY \& LAUREN STEWART \\ School of Civil and Environmental Engineering, Georgia Institute of Technology, USA
}

\begin{abstract}
There is a need for renewable building materials that are suitable replacements for conventional building materials such as steel and concrete. Cross-laminated timber (CLT) is a relatively new composite timber product with increasing use and interest in North America due to its renewable properties. Due to the unique environmental and mechanical properties of CLT, the possibility for rapid construction, and familiarity with the base material (timber), it follows that CLT may be promising for use in temporary military housing. In order to be a material for consideration in temporary military structures, CLT must be evaluated for force protection (i.e. blast effects). To investigate this possibility, the authors used data from live blasting testing conducted by WoodWorks at the US Air Force Civil Engineer Center on multiple two-storey, single-bay CLT structures. A single degree of freedom model (SDOF) was used in conjunction with the shear analogy method to predict the behavior of the CLT structures in the elastic regime. Through the CLT SDOF model, the paper highlights the necessity for further testing of CLT under blast loadings to quantify the effects of shear, boundary conditions, dynamic strength, and other properties.

Keywords: blast, cross-laminated timber, CLT, southern pine, spruce pine fir.
\end{abstract}

\section{INTRODUCTION}

\subsection{Cross laminated timber (CLT)}

Cross-laminated timber is a prefabricated, composite engineered wood product, which is fabricated using multiple layers of processed 2 inch $(5 \mathrm{~cm})$ nominal dimensional lumber. Each layer is laid in 90 degree alternating directions and is bonded with an adhesive specific to the application and environment (Fig. 1). Adhesives such as polyurethane, melamine, and phenolic-based adhesives are commonly used. The alternating and cross wis e orientation gives CLT high strength and stiffness [1]. Panel layers range from $5 / 8$ inches to 2 inches thick $(1.59 \mathrm{~cm}$ to $5.08 \mathrm{~cm})$, with individual components measuring 2.4 inches to 9.5 inches wide $(6.10 \mathrm{~cm}$ to $24.13 \mathrm{~cm})$. Panels may be constructed up to 20 inches thick $(50.8 \mathrm{~cm})$ per the current standard rating guidance from the Engineered Wood Association (APA) [2] (Fig. 2). Panels can typically be ordered in $2 \mathrm{ft}(60.96 \mathrm{~cm}), 4 \mathrm{ft}(121.92 \mathrm{~cm}), 8 \mathrm{ft}(243.8 \mathrm{~cm})$, and $10 \mathrm{ft}(304.8 \mathrm{~cm})$ widths up to $60 \mathrm{ft}(18.29 \mathrm{~m})$ in length. CLT is suited to rapid construction because it is prefabricated and lightweight relative to other building materials. Wood is an orthotropic material, thus its mechanical properties are dependent on the direction of loading. Wood has independent properties along its three axes: longitudinal, tangential, and radial (Fig. 3) [3]. Properties such as tensile, compressive, and shear strength vary based on the loaded axis. Furthermore, the properties of wood vary based on its quality, dictated by age and quantity of imperfections such as knots, checks, and splits, for example. CLT takes advantage of these qualities by: 1) alternating layer alignment such that longitudinal properties are leveraged in both directions of the panel; and 2) allowing for lower grades of wood to be used in intermediate layers that are not oriented in the primary direction of loading, where stresses tend to be lower compared to the outer layers. This inherent capability 
allows for CLT to achieve strength in two spanning directions and allows for the use of wood that may not be suitable for structural applications if used independently.

\subsection{Mechanical properties and special considerations}

Generally, the mechanical properties for CLT are evaluated through two methods: 1) the determination of properties based on models of single boards or layers; or 2) the determination of properties based on the testing of CLT elements [5]. Because CLT is a wood composite, it is subject to variation in strength dictated by that of individual components; although component variability does not seem to dominate composite behavior. Additionally, the following mechanical properties are of importance: modulus of rupture in bending,

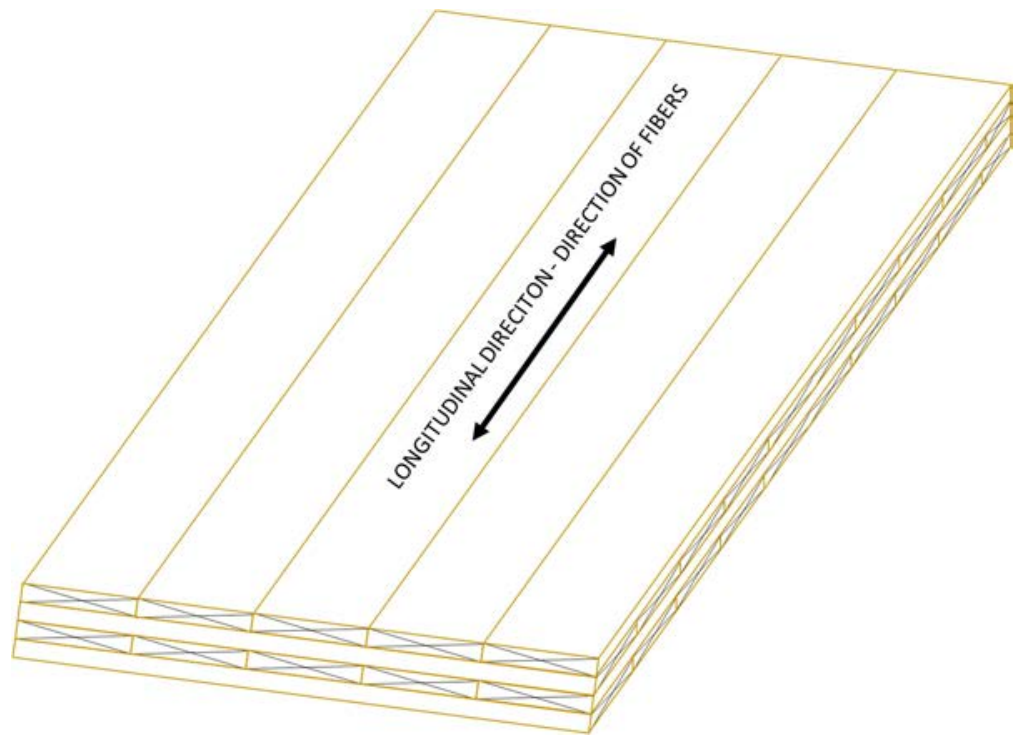

Figure 1: CLT with grain direction and alternating layers.

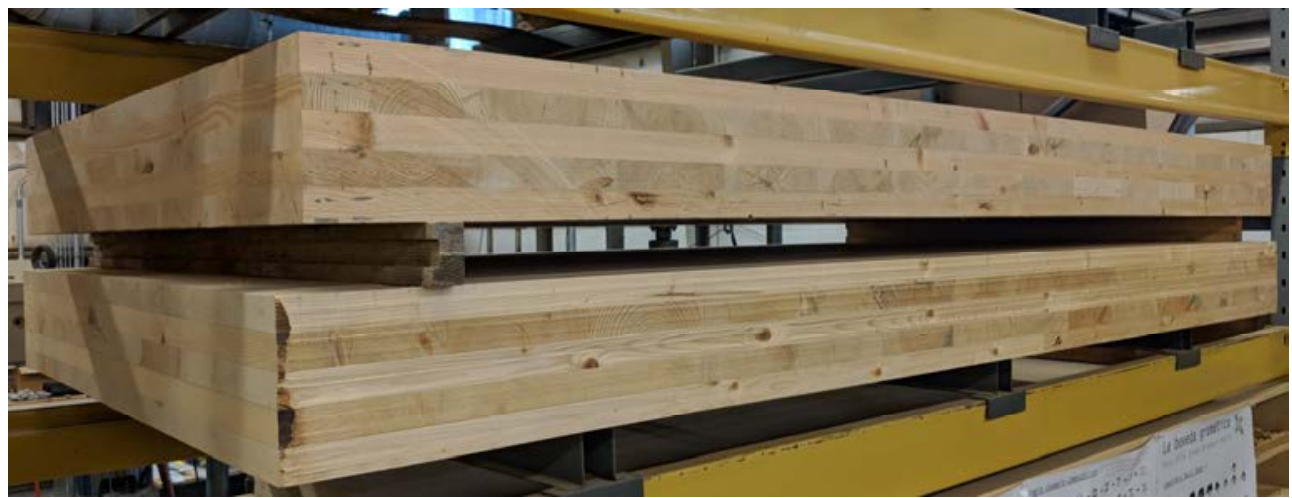

Figure 2: 5-layer CLT panels at the Georgia Institute of Technology digital fabrication laboratory. 


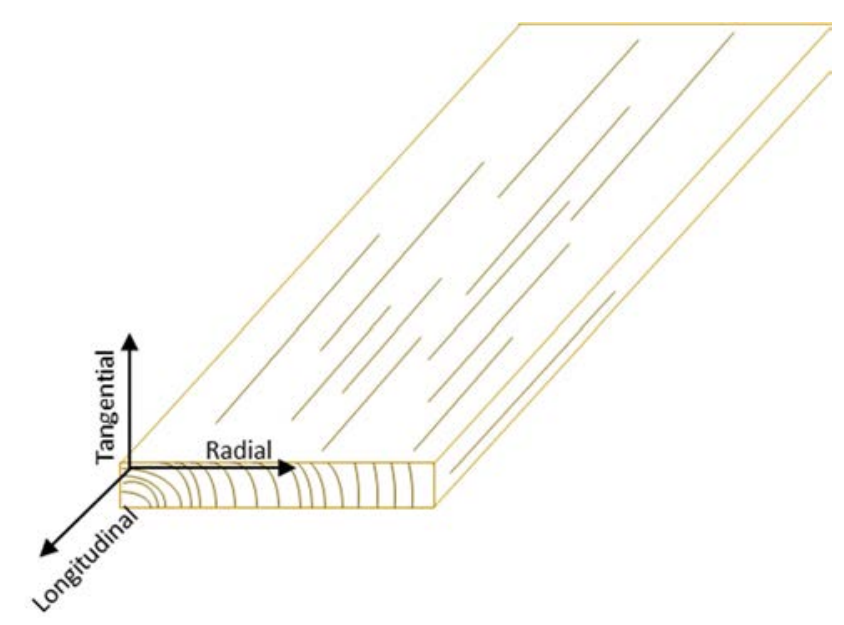

Figure 3: Three perpendicular axes in wood. (Source: adapted from [3], [4].)

maximum compressive stress parallel to the grain, maximum compressive stress perpendicular to the grain, and maximum shear stress parallel to the grain. The modulus of rupture is a measure of the load-carrying capacity and bending stress that a material can support before rupture occurs [3]. Compressive strength parallel to the grain of a wood material is dictated by the maximum stress that a material can sustain given certain a ratio of length to smallest cross sectional dimension. Shear strength is the ability to resist internal slipping along the grain lines [3].

CLT mitigates weaknesses in the radial or tangential directions because each layer is oriented perpendicularly with respect to the previous. Rolling shear, or interlaminar stress, limit states must also be considered in CLT.

\subsection{CLT system performance}

CLT has been in use as a building material in Europe for several decades. It has been shown to function predictably under normal loading conditions (e.g. gravity, etc.) and extreme loads such as fire and seismic [6], [7]. CLT's sandwich panel configuration allows the material to exhibit ductile behavior - more so than other mass load bearing materials like reinforced concrete. Furthermore, as CLT is able to behave both as a partition and structural element, it is able to provide structural redundancy and reduce the possibility of a soft storey failure mechanism [8].

Although wood is generally recognized as a flammable material, CLT panels exhibit a predictable char rate which prevents sudden loss of structural integrity. Moreover, CLT can be designed to different thicknesses by changing the layup of the panel, thereby modifying the fire resistance for 30,60 , or 90 minutes.

\section{WOODWORKS LIVE BLAST TESTING}

The resistance of CLT to ballistic or blast loadings (i.e. force protection) is not well understood as there is limited data on its performance. A series of live-blast test were conducted in October 2016 as a joint effort by WoodWorks, Karagozian and Case, and the Air Force Civil Engineer Center and funded by the US Forest Service to study the behavior of CLT structures under air-burst loads [9]. 


\subsection{Test set-up}

The first series of blast tests included three two-storey, single-bay structures constructed completely of three different CLT grades. The structures were approximately $50 \mathrm{ft}^{2}\left(4.65 \mathrm{~m}^{2}\right)$ in plan and were loaded using three explosive charges of weights $32 \mathrm{lbs}(14.51 \mathrm{~kg}), 67 \mathrm{lbs}$ $(30.39 \mathrm{~kg})$, and $199 \mathrm{lbs}(90.26 \mathrm{~kg})$. A TNT charge was set at 18 inches $(45.72 \mathrm{~cm})$ above the ground in order to simulate an air-burst. The soil in the test area was compacted and the three structures were set with their front faces along a $75 \mathrm{ft}(22.86 \mathrm{~m})$ radius from the blast center (Fig. 4).

Prior to the blast tests, the flexural behavior of the CLT panels in the major strength direction was studied with two sets of experiments. The panels were loaded with water bladders to apply a pressure load at the University of Maine. Also, shock tube testing was conducted at the Protective Design Center (PDC) at loading magnitudes within the elastic range of the panels. In addition to investigating the flexural behavior of the panels, the series of tests confirmed that the shear analogy method (i.e. an analysis method which captures the composite behavior of CLT and the interaction between longitudinal and transverse lamina) could be used to compute the stiffness and strength of the panels behaving elastically given a uniformly-applied dynamic load. An increase factor of 1.25 was used to convert CLT design standard values to impact load factored design values - this factor was based the American Wood Council's (AWC) National Design Standard (NDS) load duration factor, CD, and the 10 minute duration factor listed in the PRG 320 [10].

Each structure was constructed of a different CLT panel grade: E1, V1, and V4 (Table 1). Each panel grade was fabricated by different manufacturers and third party certified to meet the Engineered Wood Association's (APA) Standard for Performance Rated CrossLaminated Timber (PRG 320). The construction of the individual panels were as follows: 3-ply panels for walls and roof; 5-ply panels for the ground floor and second storey floor.

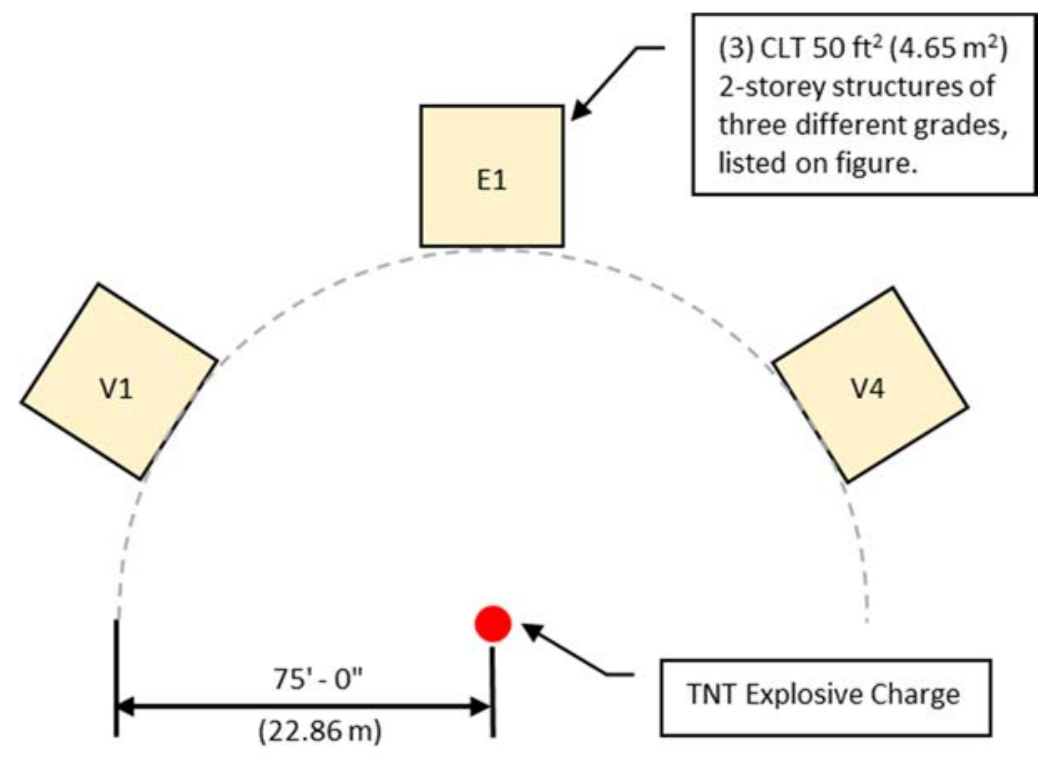

Figure 4: Orientation and position of CLT structures. 
Table 1: Wood species and commercial grade in each lamina based on grading for CLT used in live blast testing [2].

CLT grade

\begin{tabular}{l|l}
\hline E1 & $\begin{array}{l}\text { 1950f-1.7E spruce-pine-fir MSR lumber in all parallel layers and No. 3 } \\
\text { spruce-pine-fir lumber in all perpendicular layers. }\end{array}$ \\
\hline V1 & $\begin{array}{l}\text { No. 2 douglas fir-larch lumber in all parallel layers and No. 3 douglas } \\
\text { fir-larch lumber in all perpendicular layers. }\end{array}$ \\
\hline V4 & $\begin{array}{l}\text { SmartLam CLT manufactured with spruce-pine-fir south lumber in } \\
\text { accordance with custom layup combination approved by APA. }\end{array}$ \\
\hline
\end{tabular}

With regard to the components that comprised the individual panels, dimensions of the individual sawn lumber boards, such as width, finger jointing detail, and board length varied between each of the grades. Despite these differences, it should be noted that the panels conformed to the PRG 320 standard. Panels were spliced using half-lapped joints and selftapping screws of sufficient length to engage all plies (Fig. 5).

Each structure was rigidly connected to concrete foundations with steel angles. The connection to the foundation was overdesigned to ensure an increased rigidity at the connection, prevent a failure at the CLT-concrete interface, and ensure that damage was directed to the CLT panels. Internal pressure and reflected pressure were measured via pressure gauges mounted inside of the structures and incident overpressure was measured via pressure gauges mounted $75 \mathrm{ft}(22.86 \mathrm{~m})$ from the explosive.

\subsection{Results}

In Test 1 and Test 2 the explosive loading was designed such that the structures exhibited behavior within the elastic range, based on results from the quasi-static tests. Knots were dislodged from the panels, but the structures exhibited no signs of damage or plastic deformation. Test 3 was designed to result in plastic deformations in the structure constructed of grade E1 paneling, the highest grade CLT paneling used in the test series. The explosive charge was designed to cause displacements 1.5 times the elastic limit of the E1 panels [10]. Following Test 3 , visible lamina fracture and plastic deformations were observed on the each of the extreme plies of the first storey walls facing the explosive.

\section{SINGLE DEGREE OF FREEDOM MODEL}

\subsection{Resistance function}

Three generalized resistance functions are currently being considered by the authors for representing CLT. These three models are shown in Fig. 6. The shapes of the initial resistance functions in the post-yield regime are based on the results of quasi-static testing and resistance functions that are typical of wood panels. The data generated in the first live test

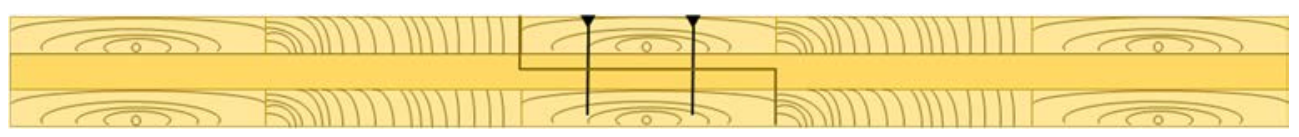

Figure 5: CLT panel splice detail. 


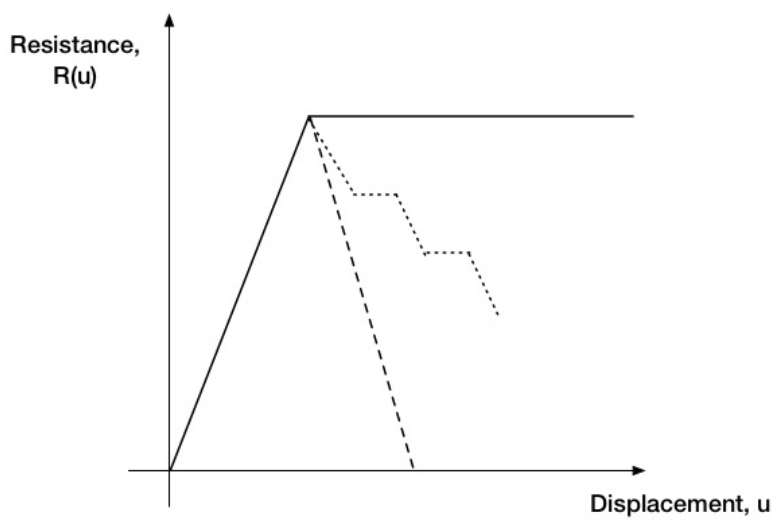

Figure 6: Resistance functions being considered for timber structures.

series fell mainly within the elastic regime and, therefore, the resistance function in this article will focus mainly on those behaviors. Additional testing and calibration is needed for behavior outside of this regime. One such dataset that was just recently published is that by [11]. For simplicity, at this stage, the model currently uses a perfectly plastic response for representing solely the rupture of the outer ply of a CLT panel.

The model also evaluates shear response based on the flexural resistance. Similar to other materials, the methodology has the capability to include rolling shear capacity, however, additional testing is required to determine when it is appropriate to include rolling shear capacity in a model. The occurrence of rolling shear failure in panels with blast loading has been simulated with shock tube tests, but has not been observed in live blast tests. This discrepancy may be due to the difference in boundary conditions established for the shock tube tests (i.e. free edges at the panel boundaries) versus those used in live tests (i.e. designed connection).

\subsection{Generalized CLT properties for resistance function}

A generalized methodology is being developed for blast load analysis of CLT using the SDOF model discussed above. The methodology allows for user-specified input for parameters that include CLT panel properties and dimensions, the explosive threat, and blast parameters. Currently four grades of CLT, based on the PRG 320, are generally specified: $\mathrm{E} 1, \mathrm{~V} 1, \mathrm{~V} 3$, and V4. The shear analogy method is used to predict the mechanical behavior of the panel. The effective bending stiffness, $E I_{\text {eff, }}$ of the panel is calculated based on eqn (1), where $E_{i}$ and $I_{i}$ are the individual ply modulus of elasticity and moment of inertia, respectively, $b_{i}$ is the width of the layer, and $h_{\mathrm{i}}$ is the thickness of each $i$ th layer

$$
B_{A}=\sum_{i=1}^{n} E_{i} I_{i}=\sum_{i=1}^{n} E_{i} b_{i} \frac{h_{i}^{3}}{12} .
$$

From this, a resistance function for the elastic regime of the specified panel is created, and the linear acceleration method is used to solve the equation of motion to find the time-history response of the element [1]. Like other SDOF methods, the results can also be used to determine force-time history, resistance-displacement, displacement-time history, and dynamic shear history (Fig. 7). Additionally, the maximum displacement of the panel, the maximum rebound displacement, and the maximum dynamic shear load are identified (Fig. 8). 

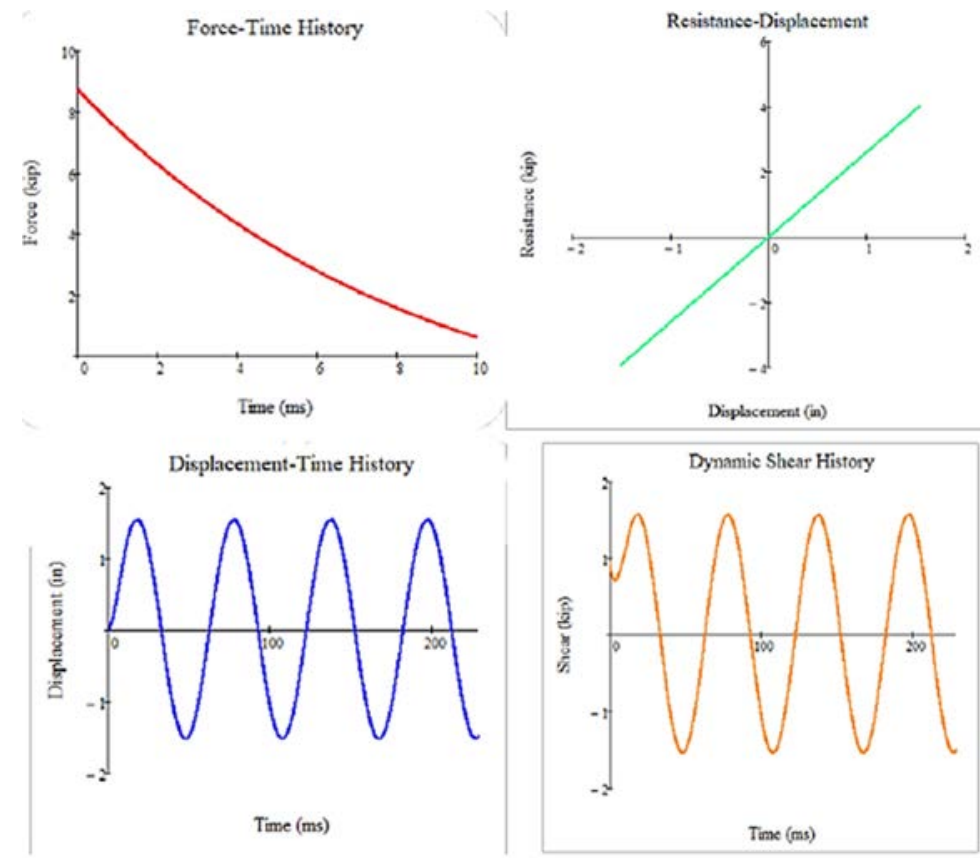

Figure 7: Example of output plots generated by SDOF model [1].

\section{Key Results:}

See plots for Force-Time History, Resistance-Displacement, Displacement-Time History, and Dynamic Shear History.

$\begin{array}{ll}\text { Maximum Displacement (in) } & \mathrm{x}_{\max }=1.545 \cdot \text { in } \\ \text { Maximum Rebound Displacement (in): } & \mathrm{x}_{\min }=-1.517 \cdot \text { in } \\ \text { Residual Displacenent (in): } & \mathrm{x}_{\mathrm{r}}=0 \cdot \text { in } \\ \text { Maximum Dynamic Shear (kip): } & \mathrm{V}_{\max }=\max (\mathrm{V})=1.572 \cdot \mathrm{kip}\end{array}$

Figure 8: Example of output data generated by SDOF model [1].

\subsection{Perfectly-plastic SDOF model comparison}

The data from the live blast tests performed by WoodWorks et al. was used to test the SDOF model. The inputs were: mechanical properties of the CLT panels, structure boundary conditions (fixed-pinned), and physical parameters of the live blast tests. Rolling shear was not considered as a parameter for this comparison because it was not an observed mechanism in the field tests. The blast load parameters from the field tests are shown in Table 2 for each of the three tests.

Table 3 compares the field test displacement data with the SDOF computations for the front wall (i.e. wall facing blast) of the first storey. Differences between SDOF computations and the displacement gauge data are shown. Large disagreements $(20 \%$ or greater) in the 
Table 2: Blast parameters for load calculations, UFC and field data [1].

\begin{tabular}{|l|c|c|c|}
\hline & Test 1 & Test 2 & Test 3 \\
\hline Peak reflected pressure, psi (MPa) & $5.05(0.0348)$ & $7.94(0.0547)$ & $13.2(0.091)$ \\
\hline Reflected impulse, psi-ms (MPa-ms) & $19.9(0.137)$ & $32.9(0.227)$ & $65.7(0.453)$ \\
\hline Duration of positive phase, ms & 8.56 & 9.42 & 11.26 \\
\hline
\end{tabular}

Table 3: Displacement comparison between field tests and elastic SDOF model.

\begin{tabular}{|l|c|c|c|c|}
\hline Test & $\begin{array}{c}\text { TNT weight, } \\
\text { lb (kg) }\end{array}$ & $\begin{array}{c}\text { Inbound displacement } \\
\text { (field test), } \\
\text { inches (cm) }\end{array}$ & $\begin{array}{c}\text { Inbound displacement } \\
\text { (SDOF model), } \\
\text { inches (cm) }\end{array}$ & $\begin{array}{c}\text { Difference } \\
\%\end{array}$ \\
\hline \multicolumn{5}{|l|}{ CLT Grade E-1, front face, ground level } \\
\hline 1 & $32(14.51)$ & $1.09(2.77)$ & $1.19(2.842)$ & 2.66 \\
\hline 2 & $67(30.39)$ & $1.96(4.98)$ & $1.831(4.651)$ & -6.58 \\
\hline 3 & $199(90.26)$ & $3.90(9.91)$ & $3.585(9.106)$ & -8.08 \\
\hline \multicolumn{5}{|l|}{ CLT Grade V-1, front face, ground level } \\
\hline 1 & $32(14.51)$ & $1.18(2.99)$ & $1.110(2.819)$ & -5.93 \\
\hline 2 & $67(30.39)$ & $2.04(5.18)$ & $1.806(4.587)$ & -11.47 \\
\hline 3 & $199(90.26)$ & $4.28(10.87)$ & $4.178(10.612)$ & -2.38 \\
\hline CLT Grade V-4, front face, ground level & & -9.63 \\
\hline 1 & $32(14.51)$ & $1.07(2.72)$ & $0.967(2.456)$ & -13.77 \\
\hline 2 & $67(30.39)$ & $1.83(4.65)$ & $1.578(4.008)$ & $\mathbf{- 2 4 . 7 9}$ \\
\hline 3 & $199(90.26)$ & $4.57(11.61)$ & $3.437(8.730)$ & \\
\hline
\end{tabular}

models prediction versus actual values are highlighted in bold. The large disagreements occurred in the visually graded CLT panels during the third test, where the model predicted rupture in the panel (i.e. inelastic behavior). The results indicated that the perfectly-plastic SDOF model is able to predict the maximum inbound displacement of the CLT system within $13 \%$ in all cases, except for the test that resulted in permanent deformation. This suggests that the CLT stiffness was adequately captured (even without a DIF), but its post-yield behavior may not be adequately models. Discussions on model improvement are given in Section 5 .

\section{FUTURE WORK}

\subsection{Inclusion of dynamic increase factor}

The results produced in Section 3 did not include any increase factors on the strength values. The stiffness was calculated using the shear analogy method and essentially combines the stiffness from each of the layers to compute a global effective value for EI. Despite this, the SDOF results in the elastic regime are within $13 \%$ of the measured displacement. For more accurate results, especially in those that utilize the dynamic yield strengths, a dynamic increase factor (DIF) should be included to account for the increase in strength at higher loading rates. Initial investigations on this increase factor have given a range from 1.2-1.35 as appropriate values based on a limited amount of testing. The largest study, by Poulin et al. 
[11] recommends a value of 1.28. It is expected that the inclusion of this factor will decrease the displacements predicted by the model and will better predict the post-peak response.

\subsection{Quantification of boundary conditions for CLT connections}

One of the biggest factors contributing to the model's ability to predict the response is the incorporation of appropriate boundary conditions. The physical testing consisted of relatively robust bolted connections at the base of the first floor wall and a bolted, but less stiff connection at the upper portion of the wall. The model comparisons derived in this article assumed a fixed-fixed support condition. The selection of this condition likely was the main contributor to the majority of the displacements being under-predicted (negative percent difference).

The cooperative team responsible for the field experiments produced an SDOF analysis model, independent of the author's research, for comparison with the field results. The model assumed simply-supported boundary conditions (i.e. pin-roller). This model predicted displacements that exceeded measured field test values. The discrepancy between the field test and the model was attributed to the difference between the boundary conditions used in the model and those constructed; specifically, that restraint of rotation was not captured in the SDOF model [10].

The results of the two independent studies indicate that the connections tested, like all physical connections, fall somewhere between an idealized fixed condition and a pin condition. Additional research is needed to determine appropriate values for rotational springs and or best-suited idealized connections for different types of CLT connections.

\subsection{Incorporation of shear}

The field tests conducted resulted in behavior that was dominated by the flexural response of the panel. The boundary conditions and loading regimes did not induce any shear-dominated responses in the panel. As such, a resistance function derived from flexural properties works well to predict the behavior. As mentioned above, shock tube tests conducted on CLT panels with different boundary conditions and far outside the elastic regime noted failures dominated by shear (e.g. rolling shear). Because of this, it is recommended that shear be checked as part of a design and analysis process. Development of methodology to quantify the governing shear response for generic panels of CLT will likely require additional testing and analysis.

\section{CONCLUSIONS}

Cross laminated timber has the potential to be utilized for temporary military construction and this article specifically highlights its potential to be used in force protection scenarios. This paper provides the initial research done to develop simple predictive models for use in design. Using data from a relatively small number of external experiments, an initial SDOF model methodology was generalized to predict the CLT's response. This model, while relatively rudimentary, is able to predict the response in the elastic regime within a reasonable amount of error. Most importantly, this research acknowledges and identifies the areas needed to future research in order to better develop generalized resistance functions for CLT of varying wood species and number of panels.

\section{ACKNOWLEDGEMENTS}

The authors would like to acknowledge WoodWorks and specifically, Lisa Podesto for providing the data from the field blast experiments for our research on temporary military construction. Additionally, the authors would like to thank Karagozian and Case, specifically 
Mark Weaver for his generous collaboration. This work was partially supported by the United States Forest Service (USFS) through the Wood Innovations Grant under USFS Domestic Grant 17-DG-11083150-008. Any opinions, findings, and conclusions or recommendations expressed in this material are those of the authors and do not necessarily reflect the views of the United States Forest Service.

\section{REFERENCES}

[1] Sanborn, K., Exploring cross-laminated timber use for temporary military structures: ballistic considerations. PhD thesis, Georgia Institute of Technology: Atlanta, GA, 2018.

[2] The Engineered Wood Association (APA), American National Standard: Standard for Performance-Rate Cross-Laminated Timber ANSI/APA PRG 320-2012, The Engineered Wood Association (APA): Tacoma, WA, 2012.

[3] Ross, R.J., Wood Handbook: Wood as an Engineering Material, US Department of Agriculture, Forest Service, Forest Products Laboratory: Madison, WI, 2010.

[4] LeVan, S.L. \& Rowell, R.M., The Chemistry of Solid Wood, American Chemical Society: Washington, DC, 1984.

[5] Bradner, R., Flatscher, G., Ringhofer, A., Schickhofer, G. \& Thiel, A., Cross laminated timber (CLT): Overview and development. European Journal of Wood and Wood Products, 2016.

[6] Shiling, P., Van De Lindt, J.W. \& Popovski, M., Approximate R-factor for CLT walls in multi-storey buildings. Journal of Architectural Engineering, 19, pp. 245-255, 2013.

[7] Cecotti, A., Sandhaas, C., Okabe, M., Yasumura, M., Minowa, C. \& Kawai, N., SOFIE Project - 3D shaking table test on a seven-storey full-scale cross-laminated timber building. Earthquake Engineering \& Structural Dynamics, 42, pp. 2003-2021, 2013.

[8] Karacabeyli, E. \& Douglas, B., CLT Handbook (Cross-Laminated Timber) U.S. Edition, 2013.

[9] WoodWorks, Leads Blast Testing Project for Cross-Laminated Timber, WoodWorks Wood Products Council: Washington, DC, 12 Dec. 2016.

[10] Weirer, M.K., O’Laughlin, C. \& Newberry, C.M. (eds), Blast resistance of crosslaminated timber construction. Presented at International Symposium on the Interactions of the Effects of Munitions with Structures (17th ISIEMS), Bad Neuenahr, Germany, 2017.

[11] Poulin, M., Viau, C., Lacroix, D.N. \& Doudak, G., Experimental and analytical investigation of cross-laminated timber panels subjected to out-of-plane blast loads. Journal of Structural Engineering, 144, 04017197, 2018. 